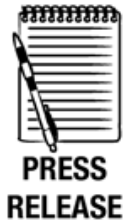

- An additional appendix is published online only. To view this file please visit the journa online (http://sti.bmj.com)

Health Protection Agency, HIV and STI Department, London, UK

\section{Correspondence to}

Dr Kate Soldan, Health

Protection Agency, 61 Colindale

Avenue, London NW9 5E0, UK:

kate.soldan@hpa.org.uk

Accepted 7 June 2011

Published Online First

3 August 2011

\title{
Genital warts and cost of care in England
}

\author{
Sarika Desai, Sally Wetten, Sarah C Woodhall, Lindsey Peters, Gwenda Hughes, \\ Kate Soldan
}

\begin{abstract}
Objectives To estimate the total number of cases of, and cost of care for, genital warts (GWs) in England, to inform economic evaluations of human papillomavirus vaccination.

Methods The number of GW cases seen in general practices (GPs) and in genitourinary medicine (GUM) clinics was estimated using the General Practice Research Database and the GUM Clinic Activity Dataset. The overlap in care of cases in the two settings was estimated. The calculated costs of care in GP and hospitals were added to the costs of care in GUM clinics (estimated elsewhere) to estimate the cost of care for GWs in England.
\end{abstract}

Results In England, in 2008, GP and GUM saw 80531 new (157/100 000 population) and 68259 recurrent (133/100 000 population) episodes, giving a total of 148790 episodes of care of GWs (289/100 000 population). Seventy-three per cent of cases were seen only in GUM clinics, 22\% were seen by a GP before being referred to GUM, and $5 \%$ by GPs only. Hospital care was given in $1.3 \%$ of cases and contributed $8 \%$ of the costs. The average cost of care per episode was $£ 113$, and the estimated annual cost of care in England was $£ 16.8$ million.

Conclusions This study provides a fairly comprehensive measure of GW frequency and care in England. GWs exert a considerable impact on health services, a large proportion of which could be prevented through immunisation using the quadrivalent human papillomavirus vaccine.

\section{INTRODUCTION}

Genital warts (GWs) are benign epithelial tumours caused by infections with human papillomavirus (HPV). They are the most common viral sexually transmitted infection (STI) diagnosed among genitourinary medicine (GUM) clinic attendees in England, with 78000 newly diagnosed cases reported by GUM clinics in 2009 (incidence of newly GUM-diagnosed GW cases of 152/100 000 population; 166/100000 male and 138/100000 female). Diagnosis rates are highest in 16-19 and 20-24-year-old women and men, respectively. ${ }^{1}$ There are a number of home and clinic treatments available, which can be long and painful and have variable success rates. ${ }^{2} \mathrm{GW}$ recurrence is also common, with $\sim 47000$ diagnoses reported by GUM clinics in 2009 (92/100 000 population). ${ }^{1}$

Two HPV vaccines are available for use in the UK-one bivalent, the other quadrivalent. Both vaccines have demonstrated protection against HPV types $16 / 18$, which cause over $70 \%$ of cervical cancer cases in women. ${ }^{34}$ The quadrivalent vaccine additionally protects against HPV6/11 infections and has been shown to prevent GWs in clinical trials. ${ }^{5}$ While reductions in disease due to HPV16/ 18 may not be evident for many years, vaccinating with the quadrivalent vaccine should result in a quite rapid measurable reduction in GW incidence. Australia introduced the quadrivalent vaccine in 2007 for women under age 27, and, after 1 year, saw a decline of over $25 \%$ in women of this age presenting with GWs at sexual health clinics, ${ }^{67}$ as well as some herd-immunity effect in young heterosexual men.

The potential savings to the health service from GW prevention by the quadrivalent vaccine were considered in the economic evaluation of vaccine choice in 2007 in the UK. ${ }^{8}$ At that point the bivalent vaccine was chosen for the first 3 years of the immunisation programme, ${ }^{9}$ and, since September 2008, HPV16/18 vaccination has been offered routinely to schoolgirls aged $12-13$ years, and a 2-year catch-up campaign has offered vaccination to girls up to 18 years. By 2010, this immunisation programme achieved a three-dose coverage of over $84 \%$ in the routine and over $47 \%$ in the 17-18-year-old catch-up cohorts. ${ }^{10}$ The delivery of HPV16/18 bivalent vaccine is not expected to reduce the incidence of HPV6/11associated GWs, or other 6/11-related diseases including recurrent respiratory papillomatosis and some low-grade cervical lesions.

Here, we estimate the total numbers of GW episodes seen in GUM clinics, GP, or both and estimate an overall incidence of new GW episodes We also estimate the cost of GUM, GP and hospital care for GWs in England.

\section{METHODS}

\section{Annual incidence of GWs in England}

Diagnoses made in two healthcare settings were used to estimate the overall rate of GWs in England: (1) episodes occurring between 2006 and mid-2008 in the General Practice Research Database (GPRD), which is a sentinel system that covers $\sim 6 \%$ of patients registered with GPs in England ${ }^{11}$; (2) the GUM Clinic Activity Dataset (GUMCAD) in 2008 and 2009, which collects data on all visits and diagnoses in GUM clinics.

For all cases (first and recurrent), we defined an episode of care as the period of time between the first and last attendance for that occurrence of GWs, where the interval between attendances was less than or equal to 8 weeks ( 56 days). This interval was based on a recommendation by GUM clinicians to allow for home treatment lasting for 4 weeks followed by a 4-week period for the patient to re-attend with unresolved symptoms. The findings in a contemporaneous study of the clinical unlocked scheme, see http://sti. bmi.com/site/about/unlocked. xhtml 
records for GW cases in GUM clinics $^{12}$ that an episode of care lasted, on average, 36 days-that is, well within our interval period-and that $87 \%$ of episodes had no intervals $>8$ weeks (S C Woodhall, personal communication, 2010) validated this clinical observation as the norm, and informed our sensitivity analysis of longer intervals.

Consultations for GWs in GPRD data are not coded as new or recurrent episodes, and, because of potential coding errors for $\mathrm{GW}$ cases in GUM clinics, we defined episodes of care for both settings as new or recurrent on the basis of attendance history. New episodes were defined as the first GW Read or OXMIS codes per patient in GPRD (definition and list in the online appendix). First episodes in GPRD were not necessarily new cases, as clinical history for each patient varied from 1987 to 2008 and patients may have had a GW diagnosis before this time, so our 'new' episodes in GP will be an overestimate of 'new' cases. In GUMCAD, a first episode began with the first-attack code (C11A), and, for patients with two or more C11A codes, those subsequent codes were discounted (if within 8 weeks) or included as recurrent episodes if occurring more than 8 weeks after the last attendance. For GUM clinic episodes, the attendance dates of recurrent $(\mathrm{C} 11 \mathrm{~B})$ and persistent $(\mathrm{C} 11 \mathrm{C})$ warts and of uncoded follow-ups were included. Follow-up visits within 8 weeks of a previous visit were considered part of the same episode.

To estimate the annual number of GW episodes by age group and sex, we combined data from GPRD and GUMCAD while accounting for the overlap of episodes seen in GP and GUM settings as follows. In GPRD, an episode with a referral code, or at least one diagnostic code in the referral table, or an episode with no treatment recorded was assumed to have been referred to a GUM clinic. These episodes were used to provide an estimate of the proportion referred from GP to GUM, by episode type. A second referral estimate from a contemporaneous study of GW care in GUM clinics was available for first episodes among GUM clinic attendees who reported a previous GP consultation. ${ }^{12}$ This was $42.3 \%$ (95\% CI $38.3 \%$ to $46.3 \%$ ) overall and was available by sex and age group. Referral rates for recurrent cases were not available from this study, and an overall recurrent referral rate was approximated assuming that the same number of patients was referred from GP to GUM as were referred from GP to GUM according to GPRD. Similar referral numbers were estimated for first episodes from the two approaches. We used an average of these two proportions, by episode type, to estimate the number of episodes seen in both GP and GUM. Rates of new and recurrent episodes per 100000 population were estimated using mid-2008 population figures from the Office of National Statistics. 95\% CIs calculated for these rates are not reported because they were too narrow to be a meaningful representation of uncertainty.

Episodes of care in NHS hospitals were estimated from hospital episode statistics (HES) for inpatients who had a primary diagnosis of ICD-10 code A630 (anogenital (venereal) warts) in 2008. Inpatient records included day cases admitted and discharged on the same day. Repeat episodes of care were those where the interval between attendances was $>8$ weeks. We assumed that cases seen in hospitals were referred GP or GUM clinic diagnoses, so these only added to the costs of GW care.

\section{Costs of GW care}

The cost of GP time per consultation was estimated to be $£ 35^{13}$ assuming an average consultation duration of $11.7 \mathrm{~min} .{ }^{14}$ The additional costs of time for a treatment procedure were added as $5 \mathrm{~min}$ at $£ 3 / \mathrm{min}$ ( $£ 15$ ), making the total cost of GP time for a consultation that required treatment to be $£ 50$. Unit costs for treatments were based on estimates reported elsewhere. ${ }^{12}$ The mean cost per GP episode of care was determined by summing the cost of all consultations and treatments given within the episode for (1) episodes resolved by the GP and (2) episodes referred to GUM with or without treatment, for which an additional $£ 94$ (95\% CI 84 to 104) was added for the cost of care in GUM clinics. ${ }^{12}$ For episodes only treated in GUM clinics, we used $£ 90$ (95\% CI 81 to 98) for first episodes (male: $£ 69,95 \%$ CI 61 to 77; female: £111, 95\% CI 97 to 124) and £107 (95\% CI 79 to 134) for recurrent episodes (male: $£ 108,95 \%$ CI 70 to 146; female: $£ 105,95 \%$ CI 65 to 144). ${ }^{12}$ The method for determining these costs for GUM care is described elsewhere. ${ }^{12}$ The cost of sexual health screens for GUM clinic attendees was not included, nor the cost of any other care given at GP consultation.

We estimated the cost of tertiary care using the HRG4 2008-2009 Reference Cost Grouper package ${ }^{15}$ and the NHS national schedule of reference costs for 2008-2009. ${ }^{16}$ The Grouper produces a healthcare resource group (HRG) code for each hospital episode, which we linked to the schedule of reference costs and estimated national average hospital costs with lower and upper quartiles. Costs also included excess bed days and drug prescription costs. HRG codes that were unrelated to GWs were excluded. The total annual cost of care for GWs was estimated by combining total costs in all three settings.

\section{Sensitivity analyses}

We allocated uncoded follow-ups to other co-diagnosed STIs and we varied the interval between attendances within an episode in order to determine the impact of this on the number of recurrences and associated costs. The different intervals tested were 12,16 and 24 weeks as the maximum plausible interval between attendances within a single episode under care in the UK. Longer intervals were considered more likely to cause errors of underestimation of episodes.

We also varied the assumption that no treatment recorded in GP care implied a referral to GUM in $100 \%$ of such cases, instead assuming only that $90 \%$ or $80 \%$ of such cases were referred to GUM.

\section{RESULTS \\ Impact of GWs in England GP episodes of care}

Between 2006 and mid-2008, there were 5243 episodes of care for GWs in GPRD, of which $82 \%$ were new episodes. Fifty-one per cent of episodes were among women, and the median age (male and female) was 26 years (IOR 21-36). The majority of episodes (89\%) had one GP consultation only (range 1-17 consultations/episode), of which three-quarters were referred on to GUM. For episodes that had two consultations (8\%), the median duration of episode of care was 12 days (range 2-57 days), and, for episodes with three or more consultations, it was 48 days (range 4-331 days). Eighty-one per cent (95\% CI 80 to 83 ) of first and $43 \%$ (95\% CI $39 \%$ to $46 \%$ ) of recurrent episodes were referred to GUM. Home treatment with imiquimod $(n=357)$ or podophyllotoxin $(n=1147)$ was prescribed more often than GP treatments $(n=326)$. There were, on average, 2097 (95\% CI 2041 to 2155) episodes of care/year, and, after extrapolation to the total population under GP care in England, the age-adjusted annual number of GW episodes seen by GP was 39645 (32 496 new and 7149 recurrent episodes).

\section{GUM clinic episodes of care}

There were 155389 new and 128149 recurrent cases of GWs identified from GUM clinic data during 2008 and 2009, giving an 
Figure 1 Estimated annual number of genital wart (GW) diagnoses and rate per 100000 population in each setting by episode type and sex. Numbers are extrapolated to England using Office of National Statistics population data by sex while overall numbers are age adjusted and do not equal sum of male and female patients. ${ }^{*}$ Rates are per 100000 population. GP, general practice; GUM, genitourinary medicine.

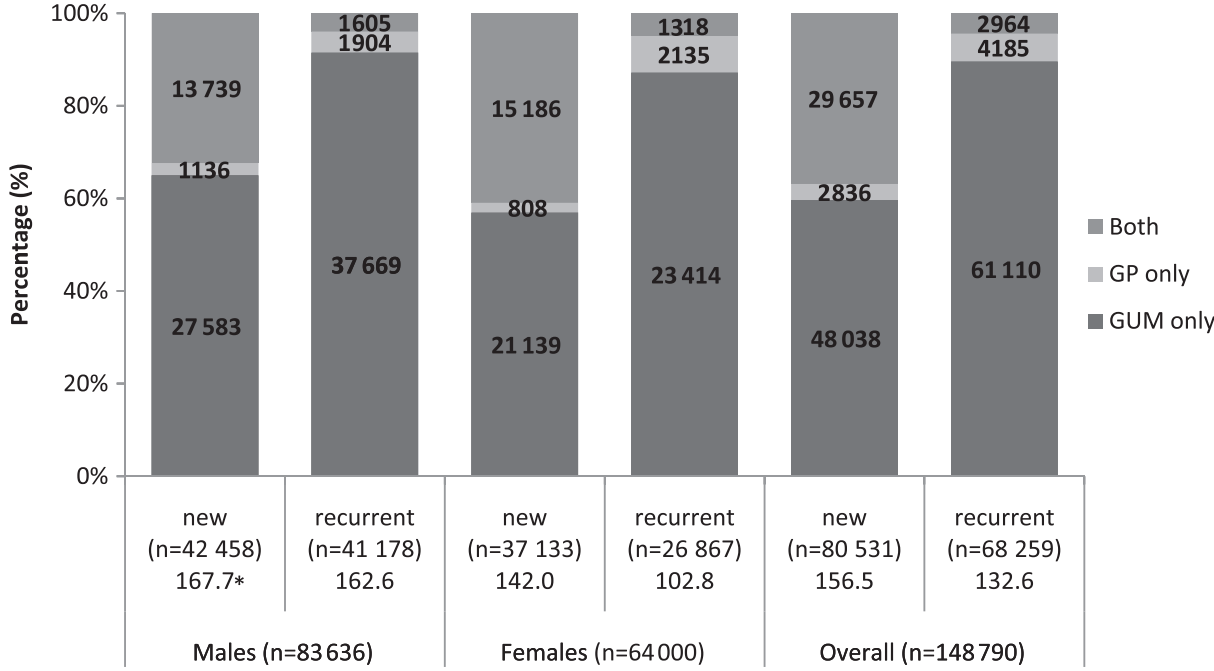

annual average of 141770 cases (77695 new, 64075 recurrent). Fifty-seven per cent of all cases were among men (slightly lower for new episodes at $53 \%$ ), and the median age of GUM attendees was 25 years (IOR 21-33).

\section{HES episodes of care}

There were 1978 episodes of care for GWs in NHS hospitals in 2008. Of these, 1807 (91\%) were first episodes of hospital care and 171 were repeat treatments. Fifty-nine per cent of episodes were in men, and the median age was higher than for episodes seen in GP and GUM settings (40 years, IQR 27-56), although age was missing for $57 \%$. Excision of perianal warts (40\%) was the most common operative procedure, followed by cauterisation or excision of lesions of the vulva (12\%), anus $(7 \%)$ and penis $(5 \%)$. For $87 \%$ of episodes, patients were admitted and discharged on the same day. The maximum duration of hospital stay for patients with a GW diagnosis alone was 5 days.

\section{Incidence of anogenital warts in GUM and GP in England}

Our estimate of having received care at both settings was 37\% for first and 4\% for recurrent episodes. On the basis of these referral patterns, $\sim 30000$ new and 3000 recurrent episodes annually were seen by GP and subsequently by GUM (figure 1). After this overlap had been accounted for, the total annual number of GW cases was $~ 149000$. Fifty-three per cent of new and $60 \%$ of recurrent episodes were in men. The estimated incidence for all episodes was 289/100 000 population, for new episodes of GW, it was $157 / 100000$ population, and the rate of recurrences was 133/100 000 population (figure 1 ). The incidence of new episodes was $168 / 100000$ and 142/100 000 population among men and women (all ages), respectively, and peaked among 20-24 year olds (755/100 000 population) for both sexes combined (figure 2).

\section{Total cost of care for GWs in England}

The average cost per episode of care resolved by GPs was $£ 79$ and per episode seen by GP and GUM clinicians was £138. The annual cost of care in GP and GUM, combined, was approximately $£ 15.3$ million. The average cost per episode of hospital care was $£ 718$ and the annual cost of hospital care was approximately $£ 1.4$ million. The estimated cost per episode of care for all settings was $£ 113$ (95\% CI 104 to 121). Costs were higher for female than male patients. The estimated annual cost of care for GWs in England, in GP, GUM and hospitals was $£ 16.8$ million (95\% CI 15.5 to 18.0 ) (table 1 ).

\section{Sensitivity analyses}

Accounting for other STI diagnoses that could result in uncoded follow-ups reduced the number of follow-ups attributable to GWs and hence reduced the number of GW episodes in GUM by $3 \%$ (to 130000). The number of recurrent episodes decreased from 68000 to 60000 (ie, by 12\%), 54000 (ie, by 21\%) and 47000 (ie, 30\%) when the interval between attendances within an episode was increased from 8 weeks to 12,16 and 24 weeks, respectively. Changing the episode definition also increased the cost of GP-only care from $£ 79$ (8 week definition) to $£ 85$ when an interval of 24 weeks was used. Increasing the interval between attendances had a greater impact on decreasing the numbers of recurrent episodes than on increasing the cost per episode treated by GPs, and resulted in a lowered total annual cost of care to $£ 14.7$ million (95\% CI 13.6 to 15.8 ) - that is, $\sim 10 \%$ lower-for an episode definition allowing 24-week intervals.

Assuming that $10 \%$ or $20 \%$ of GP cases with no treatment recorded were, in fact, not referred to GUM increased the number only seen by GP (and total cases) by 1000-2000.

\section{DISCUSSION}

By combining analyses of data from GUM, GP and hospital, we estimate 149000 cases of GWs in England annually, at a cost to diagnose and treat in the region of $£ 17$ million. Three-quarters of cases were managed only in GUM clinics, a further fifth were seen in GP before being referred to a GUM clinic, and the

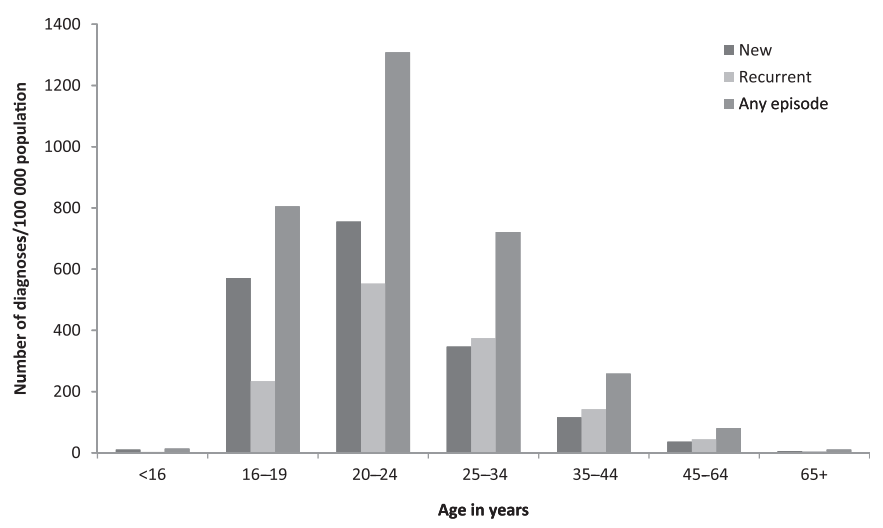

Figure 2 Estimated annual number of genital wart (GW) diagnoses per 100000 population in England by episode type and age group. 
Table 1 Estimated cost for episodes of care by gender, GPs, GUM clinics and hospitals*

\begin{tabular}{|c|c|c|c|c|c|}
\hline & $\mathbf{n}$ & Males $£(95 \% \mathrm{Cl})$ & Females $£(95 \%$ CI) & $\begin{array}{l}\text { Per episode }(£) \\
(95 \% \mathrm{CI})\end{array}$ & $\begin{array}{l}\text { Total (£, in millions) } \\
(95 \% \mathrm{CI})\end{array}$ \\
\hline GP only & 7000 & 79 (75 to 83$)$ & 79 (76 to 82$)$ & 79 (77 to 82 ) & 0.55 (0.54 to 0.57$)$ \\
\hline New episodes & 3000 & 76 (72 to 77$)$ & 77 (73 to 81$)$ & 76 (73 to 79$)$ & $0.23(0.22$ to 0.24$)$ \\
\hline $\mathrm{GP} \rightarrow \mathrm{GUM}$ & 33000 & 119 (107 to 130$)$ & 154 (139 to 169$)$ & 138 (127 to 148$)$ & 4.54 (4.18 to 4.89 ) \\
\hline New cases & 30000 & 118 (106 to 130$)$ & 153 (138 to 168 ) & 132 (123 to 142 ) & 3.97 (3.69 to 4.26$)$ \\
\hline Recurrent cases & 3000 & 124 (112 to 136$)$ & $161(146$ to 176$)$ & 157 (128 to 185$)$ & $0.47(0.39$ to 0.55$)$ \\
\hline Recurrent cases & 61000 & 108 (70 to 146$)$ & 105 (65 to 144$)$ & 107 (79 to 134$)$ & 6.51 (4.81 to 8.20$)$ \\
\hline Total GP and GUM & 149000 & $\mathrm{n} / \mathrm{c} \ddagger$ & $\mathrm{n} / \mathrm{c} \neq$ & $\mathrm{n} / \mathrm{c} \neq$ & 15.34 (14.16 to 16.52$)$ \\
\hline New episodes & 81000 & & & & 8.51 (8.00 to 9.01 ) \\
\hline Recurrent episodes & 68000 & & & & 7.31 (5.62 to 9.00$)$ \\
\hline Hospital-any & 1978 & 724 (551 to 898) & 714 (508 to 920 ) & 718 (531 to 904 ) & $1.42(0.98$ to 1.72$)$ \\
\hline Total of all settings & 149000 & 97 (87 to 107 ) & $129(117$ to 140$)$ & 113 (104 to 121$)$ & $16.76(15.53$ to 18.00$)$ \\
\hline
\end{tabular}

*All figures have been rounded to the nearest 1000 and the total may not equal the sum of component costs.

†Source of GUM clinic episode costs: S C Woodhall, personal communication.

$\ddagger$ Not calculated.

GP, general practice; GUM, genitourinary medicine; n/c, not calculated.

remainder $(5 \%)$ were cared for by GP only. Hospital care was given to $1 \%$ of all cases. The costs incurred by GUM, GP and hospital services were $80 \%, 12 \%$ and $8 \%$, respectively.

Our sensitivity analysis showed that our methods for estimating the overlap between GP and GUM care may have slightly $(\sim 1 \%)$ underestimated the total number of cases, while our inclusion of uncoded follow-up visits and our method for determining recurrent cases may have overestimated these (by $3 \%$ and up to $30 \%$, respectively). Our estimates do not include GW diagnoses and costs from a number of other health services which provide sexual health screens in England, but for which no surveillance data are currently available. ${ }^{17}$ The HRG method has not been previously used to estimate costs of GWs in hospitals, and possible inclusion of unrelated operative codes and other errors of the nature found in a study of diagnoses and operative procedures for otolaryngology ${ }^{18}$ may have caused overor under-estimation of hospital costs. Hospital costs may have been underestimated by exclusion of GW codes other than the primary diagnosis and of outpatient care. However, we understand that the majority of hospital treatments register as 'day case' inpatients in HES.

Our rates of GW episodes were broadly consistent with estimates reported for the UK for 1998-2000 of GWs (new and recurrent) in GP and GUM. ${ }^{19}$ Our incidence of new and recurrent GWs in England is higher than reported from some other European countries. ${ }^{20-22}$ Australia has reported higher rates without distinguishing new or recurrent cases, ${ }^{23}$ while the North American studies reported lower rates. ${ }^{24-26}$ Differences in the method used to determine recurrent cases probably contribute to these differences (table 2). Higher rates in England may also reflect higher-risk sexual behaviours, as evident from higher rates of some other STIs and teenage pregnancies.

Our estimate for recurrent episodes is higher than that reported by the Health Protection Agency for GUM clinics

Table 2 Studies of genital wart (GW) incidence

\begin{tabular}{|c|c|c|c|c|c|}
\hline Study & Country, year & $\begin{array}{l}\text { Interval for defining } \\
\text { recurrence (months) }\end{array}$ & Age and sex & Episode type & $\begin{array}{l}\text { Annual incidence } / 100000 \\
\text { population }(95 \% \mathrm{Cl})^{*}\end{array}$ \\
\hline \multirow[t]{5}{*}{ Present $†$} & \multirow[t]{2}{*}{ England, 2008-2009 } & \multirow[t]{2}{*}{2 (base case) } & \multirow[t]{2}{*}{ All } & New & 157 \\
\hline & & & & Recurrent & 133 \\
\hline & \multirow[t]{3}{*}{ Sensitivity analyses } & 3 & All & Recurrent & 116 \\
\hline & & 4 & All & Recurrent & 105 \\
\hline & & 6 & All & Recurrent & 91 \\
\hline \multirow[t]{2}{*}{ Cassell et al ${ }^{19}$} & \multirow[t]{2}{*}{ UK, 1998-2000 } & \multirow[t]{2}{*}{ Not reported } & \multirow[t]{2}{*}{ All } & \multirow[t]{2}{*}{ All } & 307.6 (305.5 to 309.8$)$ males \\
\hline & & & & & 236.2 (234.2 to 238.4 ) females \\
\hline \multicolumn{6}{|c|}{ Other studies of GW incidence } \\
\hline \multirow[t]{3}{*}{ Castellsagué et al ${ }^{20}$} & \multirow[t]{3}{*}{ Spain, 2005} & \multirow[t]{3}{*}{ Not reported } & \multirow[t]{3}{*}{$14-64$ years } & New & 117.86 \\
\hline & & & & Recurrent & 42.57 \\
\hline & & & & Resistant & 21.72 \\
\hline \multirow[t]{2}{*}{ Hillemanns et $a l^{21}$} & \multirow[t]{2}{*}{ Germany, 2005} & \multirow[t]{2}{*}{ Not reported } & \multirow[t]{2}{*}{ 14-65-year-old females } & New & $114(109$ to 119$)$ \\
\hline & & & & Recurrent & 35 (32 to 37$)$ \\
\hline Lukasiewicz et al ${ }^{22}$ & France, 2000 & Not reported & All & All & 107 \\
\hline Pirotta et $a l^{23}$ & Australia, 2000-2006 & Not reported & All & All & $219(188$ to 249$) \ddagger$ \\
\hline Marra et $\left.a\right|^{24}$ & Canada, 2006 & 12 & $>15$ years & All & $126 \neq$ \\
\hline Hoy et $a l^{25}$ & USA, 2004 & 12 & All & All & $120 \neq$ \\
\hline \multirow[t]{2}{*}{ Insigna et $\left.a\right|^{26}$} & \multirow[t]{2}{*}{ USA, 2000} & \multirow[t]{2}{*}{12} & \multirow[t]{2}{*}{ All } & \multirow[t]{2}{*}{ All } & 165 (males) $\neq$ \\
\hline & & & & & 167 (females) \\
\hline
\end{tabular}




\section{Key messages}

In 2008, the estimated annual incidence of new episodes of genital warts (GWs) was $157 / 100000$ population, and the rate of recurrent episodes was up to $133 / 100000$ population.

- The average cost of an episode of care for GWs (in genitourinary medicine (GUM), general practice (GP) and hospitals) was $£ 113$ (95\% Cl 104 to 121).

- The total annual cost of care for GWs in England was approximately £16.8 million (95\% CI 15.5 to 18.0$)$, with over three-quarters of these costs incurred in GUM clinics.

(92/100 000 population) partly because we included GP episodes and defined recurrence from attendance history, but also because some episodes of care for re-registered persistent cases would have been counted as recurrent cases. The combined rate of persistent GWs reported by GUM clinics to the Health Protection Agency $(29 / 100000)$ and recurrent GWs was more comparable at $121 / 100000$.

Costs for care of GWs have been reported from Spain $(€ 833),{ }^{20}$ Germany $(€ 550)^{21}$ and France $\left(€ 342\right.$ females), ${ }^{27}$ all in 2005, and from Australia (A $\$ 251$, €178 for males and A\$386, $€ 274$ for females) ${ }^{23}$ in 2009 and Canada (\$C190, €139) in 2006. ${ }^{24}$ Comparison with our cost of care per episode, for three settings in England ( $£ 113$ equivalent to $€ 130$, January 2011) is not straightforward because of differences in settings studied and case definitions, including episode duration.

Sexual health screens, which should be offered to all GUM clinic attendees diagnosed with an STI, were not included in our totals. On the basis of a cost of $£ 52$ per screen ${ }^{28}$ this would cost an additional $£ 7.8 \mathrm{~m}$ annually, bringing our total NHS cost to over $£ 24.6 \mathrm{~m}$.

GWs exert a considerable impact on health services in England. These estimates of this impact should contribute to assessing the potential benefits of HPV vaccines that protect against HPV6/11.

Acknowledgements We thank Tom Nichols and Andrew Grant for providing statistical support and Mandy Yung and Jackie Cassell for their contributions in developing the Read/OXMIS codes used in the GPRD analysis. We also thank GPRD for providing the data on genital warts in general practice for this study and all the practices that contribute to the GPRD. We are grateful to Julia Stowe and the Hospital Episode Statistics (The Information Centre for health and social care) for providing the HES data used for this study. We would also like to acknowledge all GUM clinics in England for their data submissions.

Funding Department of Health, Wellington House 135-155 Waterloo Road, London SE1 8UG, UK.

Competing interests The authors' institution has received money from the Department of Health for STI and HPV surveillance. SW was a GSK employee and has stocks in the company.

Contributors SD conducted analysis of HES data and drafted the manuscript. SW performed analysis of GPRD data, SCW contributed data from a separate GUM clinic study, and LP analysed GUMCAD data. All authors contributed to the design and interpretation of the analysis and made substantive contributions to the final version of the manuscript.

Provenance and peer review Not commissioned; externally peer reviewed.

\section{REFERENCES}

1. Health Protection Agency. STI Annual Data Tables. 2009. http://www.hpa.org.uk/ web/HPAweb\&HPAwebStandard/HPAweb_C/1203348026613 laccessed 25 Aug 2010)
2. British Association for Sexual Health and HIV. United Kingdom National Guideline on the Management of Ano-genital Warts. 2007. http://www.bashh.org/ documents/86/86.pdf (accessed 24 Aug 2010).

3. De Carvalho N, Teixeira J, Roteli-Martins CM, et al. Sustained efficacy and immunogenicity of the HPV-16/18 ASO4-adjuvanted vaccine up to 7.3 years in young adult women. Vaccine 2010;28:6247-55.

4. The FUTURE II Group. Effect of prophylactic human papillomavirus L1 virus-like particle vaccine on risk of cervical intraepithelial neoplasia grade 2, grade 3 , and adenocarcinoma in situ: a combined analysis of four randomised clinical trials. Lancet 2007;369:1861-8.

5. Dillner J, Kjaer SK, Wheeler CM, et al; The FUTURE I/II Study Group. Four year efficacy of prophylactic human papillomavirus quadrivalent vaccine against low grade cervical, vulvar, and vaginal intraepithelial neoplasia and anogenital warts: randomised controlled trial. BMJ 2010;341:c3493.

6. Fairley CK, Hocking JS, Gurrin LC, et al. Rapid decline in presentations of genital warts after the implementation of a national quadrivalent human papillomavirus vaccination programme for young women. Sex Transm Infect 2009;85:499-502.

7. Donovan B, Franklin N, Guy R, et al. Quadrivalent human papillomavirus vaccination and trends in genital warts in Australia: analysis of national sentinel surveillance data. Lancet 2011;11:39-44.

8. Jit $\mathbf{M}$, Choi $\mathrm{YH}$, Edmunds J. Economic evaluation of human papillomavirus vaccination in the United Kingdom. BMJ 2008;337:a769.

9. Department of Health. Introduction of the human papillomavirus vaccine into the national immunisation programme: announcement of vaccine to be used. http:// www.dh.gov.uk/en/Publicationsandstatistics/Lettersandcirculars/ Dearcolleagueletters/DH_ 085582 (accessed 20 Sep 2010)

10. Department of Health. Annual HPV vaccine coverage in England: 2009/2010. http://www.dh.gov.uk/en/Publicationsandstatistics/Publications/ PublicationsPolicyAndGuidance/DH_123795 (accessed 10 Feb 2011).

11. Walley T, Mantgani A. The UK general practice research database. Lancet 1997;350:1097-9.

12. Woodhall SC, Jit M, Soldan K, et al. The impact of genital warts: loss of quality of life and cost of treatment in eight sexual health clinics in the UK. Sex Transm Infect 2011; 87:458-63

13. Curtis L. General practitioner-unit costs. In: Curtis L, ed. Unit costs of Health and Social Care 2009. Canterbury: University of Kent, 2009:123.

14. The Information Centre. 2006/07 UK General Practice Workload Survey. http:// www.ic.nhs.uk/webfiles/publications/gp/GP\%20Workload\%20Report.pdf laccessed 9 Aug 2010).

15. The Information Centre. The Casemix Service. HRG4 2008/09 Reference Costs Grouper. http://www.ic.nhs.uk/services/the-casemix-service/using-this-service/ reference/archived-past-groupers-and-documentation/reference-cost/hrg4-2008-09reference-costs-grouper (accessed 27 Jun 2011).

16. The Department of Health. NHS Reference Costs 2008-09. Appendix NSRC1: NHS trust reference cost schedules. http://www.dh.gov.uk/en/Publicationsandstatistics/ Publications/PublicationsPolicyAndGuidance/DH 111591 (accessed 21 Jun 2010).

17. Yung M, Denholm R, Peake J, et al. Distribution and characteristics of sexual health service provision in primary and community care in England. Int J STD AIDS 2010;21:650-2.

18. Nouraei SA, O'Hanlon S, Butler CR, et al. A multidisciplinary audit of clinical coding accuracy in otolaryngology: financial, managerial and clinical governance considerations under payment-by-results. Clin Otolaryngol 2009;34:43-51.

19. Cassell J, Mercer CH, Sutcliffe L, et al. Trends in sexually transmitted infections in general practice 1990-2000: population based study using data from the UK general practice research database. BMJ 2006;332:332-4.

20. Castellsagué $\mathbf{X}$, Cohet $C$, Puig-Tintoré LM, et al. Epidemiology and cost of treatmen of genital warts in Spain. Eur J Public Health 2009:19:106-10.

21. Hillemanns $\mathbf{P}$, Breugelmans JG, Gieseking $F$, et al. Estimation of the incidence of genital warts and the cost of illness in Germany: a cross-sectional study. BMC Infect Dis 2008;8:76.

22. Lukasiewicz $\mathbf{E}$, Aractingi S, Flahault A. Incidence and management of condylomata acuminata by French general physicians. Ann Dermatol Venereol 2002; 129:991-6.

23. Pirotta M, Stein AN, Conway EL, et al. Genital warts incidence and health care resource utilisation in Australia. Sex Transm Infect 2010;86:181-6.

24. Marra F, Ogilvie G, Colley L, et al. Epidemiology and costs associated with genita warts in Canada. Sex Transm Infect 2009;85:111-15

25. Hoy T, Singhal PK, Willey VJ, et al. Assessing incidence and economic burden of genital warts with data from a US commercially insured population. Curr Med Res Opin 2009;25:2343-51

26. Insinga RP, Dasbach EJ, Myers ER. The health and economic burden of genita warts in a set of private health plans in the United States. Clin Infect Dis 2003:36:1397-403.

27. Monsonégo J, Breugelmans JG, Bouée S, et al. Anogenital warts incidence, medical management and costs in women consulting gynaecologists in France. Gynécol Obstet Fertil 2007;35:107-13.

28. Pearce V, Grant A, Adams E. Technical Document - Phase 1 Methodology of the Proposed Integrated Sexual Health Pricing and Currencies for London. Community Sexual Health Services. London: Pathway analytics, 2009. 